\title{
Relações entre condições e organização do trabalho e os afastamentos de trabalhadores portuários de transporte*
}

\section{Working conditions and organisational aspects and the retirement of port workers of transportation}

\author{
Maria do Carmo Baracho de Alencar', Raquel Abdalla Martins Biz ${ }^{2}$
}

ALENCAR, M. C. B.; BIZ, R. A. M. Relações entre condições e organização do trabalho e os afastamentos de trabalhadores portuários de transporte. Rev. Ter. Ocup. Univ. São Paulo, v. 23, n. 3, p. 208-15, set./dez. 2012.

RESUMO: O objetivo deste estudo foi o de investigar as possíveis relações existentes entre os afastamentos de trabalhadores portuários de transporte com vínculo empregatício, e aspectos das condições e organização do trabalho, a partir das percepções dos sujeitos. Foi desenvolvido a partir de estudo de caso, de caráter descritivo e exploratório, com ênfase em análises qualitativas. Foram selecionados seis $(\mathrm{n}=6)$ trabalhadores portuários em situação de afastamento, entre eles motoristas e operadores de conjunto transportador, por meio de listagem fornecida pelo Sindicato de Trabalhadores Portuários de Santos-SP. Para a realização das entrevistas semiestruturadas, houve a elaboração de roteiro com questões sobre o perfil ocupacional, situação de afastamento, condições e aspectos da organização do trabalho, entre outras, que foram gravadas e transcritas na íntegra para análise categorial de conteúdo. Dos seis sujeitos participantes, todos eram do gênero masculino, com faixa etária entre 40 e 57 anos, quatro $(n=4)$ deles estavam afastados do trabalho por doenças na região lombar e dois $(\mathrm{n}=2)$ por transtornos mentais. Foram identificados enquanto aspectos de risco à saúde: ritmo intenso de trabalho, repetitividade, poucas pausas, jornadas extensas, condições precárias dos caminhões, pouco reconhecimento no trabalho, falta de segurança, entre outros. Sugere-se que há relações entre aspectos das condições e organização do trabalho e os afastamentos dos trabalhadores. Destaca-se a necessidade de intervenções visando à saúde e segurança no trabalho portuário.

DESCRITORES: Licença médica; Trabalho; Trabalho/psicologia; Condições de trabalho; Saúde do trabalhador; Emprego/organização \& administração; Ocupações/recursos humanos; Conduçao de veículo/psicologia; Doenças profissionais/psicologia; Estudo de caso.

\footnotetext{
*Este trabalho é parte integrante de pesquisa intitulada "Afastamentos de trabalhadores portuários e relações com condições e organização do trabalho".

Foi apresentado oralmente no evento Cuba Salud 2012 - Convención Internacional de Salud Pública/ IV Simposio Internacional de Salud Ocupacional, em 04/12/2012, em Havana- Cuba.

${ }^{1}$ Professora Doutora, Departamento de Gestão e Cuidados em Saúde, Universidade Federal de São Paulo - UNIFESP, campus da Baixada Santista, Santos, SP.

2 Terapeuta Ocupacional formada pela Universidade Federal de São Paulo-UNIFESP, campus da Baixada Santista, Santos, SP, bolsista $\mathrm{PIBIC} / \mathrm{CNPq}$.

Endereço para Correspondência: Maria do Carmo Baracho de Alencar, Universidade Federal de São Paulo, campus da Baixada Santista, rua Silva Jardim, 136, Vila Mathias, CEP 11015-020, Santos, SP, Brasil. E.mail: alencar@unifesp.br.
} 


\section{INTRODUÇÃO}

$\mathrm{O}$ trabalho tem papel estruturante para o ser humano, podendo afetar a saúde nos âmbitos físico e mental. Tanto aspectos das condições quanto da organização do trabalho podem afetar a saúde dos trabalhadores. Dejours (1992) entende por condições de trabalho, o ambiente físico (temperatura, pressão, barulho, vibração, irradiação, altitude, etc), o ambiente químico (produtos manipulados, vapores e gases tóxicos, poeiras, fumaças, etc), o ambiente biológico (vírus, bactérias, parasitas, fungos), as condições de higiene, de segurança, e as características antropométricas do posto de trabalho. Já a organização do trabalho é responsável pelas regulamentações dos processos e trabalho, assumindo papel determinante. Compreende a prescrição e divisão do trabalho, o conteúdo da tarefa, o sistema hierárquico, as modalidades de comando, relações de poder, as questões de responsabilidades, entre outros (DEJOURS, 1992). Ela pode contribuir para a melhoria dos espaços de resolução de problema ou, ao contrário, restringir as possibilidades definindo regras que inviabilizam a manifestação dos saberes acumulados ou da criatividade resultante da articulação de outras competências dos trabalhadores (ABRAHÃO; TORRES, 2004).

Dentre as várias possibilidades de inserção profissional, o trabalho portuário constitui-se como uma das mais antigas do país, e é, em geral, conhecido por ser-ocasional e, propenso a oscilações oriundas do fluxo de navios aos portos. Neste contexto, o setor vem sofrendo muitas mudanças nos últimos anos em virtude da necessidade de modernização, ou seja, da incorporação de novas tecnologias nos processos de trabalho. Para Diégues (2009) a introdução da tecnologia por um lado, facilitou o trabalho portuário, minimizando o desgaste físico e otimizando o tempo de trabalho, mas por outro, acabou reduzindo a necessidade de mão-de-obra e demandando maior especialização daqueles que permaneceram no setor. Ainda para a autora, o estabelecimento de um quadro de trabalhadores especializados varia em relação à forma de contratação vigente no porto, que depende, sobretudo, de quem exerce o controle sobre o trabalho.

No Brasil, a Lei 8.630/93, instituiu os Órgãos Gestores de Mão-de-Obra, que são responsáveis pelo cadastro e registro dos trabalhadores portuários, pela intermediação do fornecimento de mão-de-obra, por promover treinamento e habilitação profissional, arrecadação e repasse aos trabalhadores da remuneração devida pelos operadores portuários (AGUIAR et al., 2006). Conforme o Manual do Trabalho Portuário e Ementário (2001) existem duas formas de vinculação dos trabalhadores neste setor: o trabalho portuário avulso e o trabalho portuário com vínculo empregatício. É importante destacar que o processo de Modernização dos Portos, instituído pela Lei 8.630/93, abriu a possibilidade de privatização do setor, favoreceu mudanças na gestão, reestruturação e divisão do trabalho, além da introdução de novas tecnologias (DIÉGUES, 2009).

As condições ambientais do trabalho portuário segundo Stacchini (1978) sempre foram bastante desfavoráveis, insalubres e perigosas, caracterizadas pela: presença de ruídos, iluminação inadequada, exposição a produtos químicos, gases, poeiras, e calor. Em 1993, houve a promulgação da Lei de Modernização dos Portos, favorecendo a incorporação de novas tecnologias de transporte, e o estabelecimento de novos métodos de manipulação de cargas de acordo com a Convenção Internacional n ${ }^{\circ} 137$ da Organização Internacional do Trabalho.

Segundo Araújo et al. (2000), os trabalhadores que operam máquinas e equipamentos pesados como os guindasteiros, embora não apontem o esforço físico da carga, trazem enquanto fatores de risco o trabalho repetitivo e o isolamento, imposições de qualidade, rapidez, eficiência e flexibilização, que não são coerentes com os maquinários utilizados. Para esses autores, outros fatores insalubres e perigosos estão relacionados à dificuldade de comunicação, ocasionada pelo excesso de ruído e pela dificuldade de visualização devido à iluminação insuficiente. Por fim, referem que o que atenua parcialmente os impactos nocivos desse tipo de atividade é o grupo, o coletivo de trabalhadores, por meio de ações de solidariedade e de cuidados.

Neste contexto, o maior porto da América Latina, situado na cidade de Santos - São Paulo, recebe navios do mundo todo e cerca de 2 a 4 mil caminhões diariamente, número que aumenta nos períodos de safra (VILLARINHO et al., 2002). Machin et al. (2009), em pesquisa sobre esse porto, encontraram condições desfavoráveis e acidentes de trabalho. Os principais acidentes encontrados aconteceram em decorrência de movimentações inadequadas de cargas em contêineres, fluxo intenso de caminhões, máquinas e empilhadeiras na faixa do cais, pisos irregulares e pouco aderentes, más condições de visibilidade, entre outros. Atropelamentos, fraturas e quedas destacaram-se entre as principais causas de acidentes.

A pesquisa acima mostrou que os trabalhadores concebem doença como sinônimo de fraqueza e submissão, o que faz com que, muitas vezes, camuflem seus sintomas. Villarinho et al. (2002) acrescentam que os caminhoneiros inseridos neste contexto, dispunham de instalações precárias para higiene, lazer e alimentação e que desenvolviam suas atividades de forma ininterrupta, ou seja, 24 horas por 
dia, seguindo o ritmo do porto, permanecendo por longo período em seus caminhões devido à espera para carregar e descarregar as mercadorias.

Para a legislação brasileira, os acidentes de trabalho compreendem as doenças profissionais, as doenças do trabalho, acidentes de trajetos, entre outros (BRASIL,1991). Segundo o Ministério da Previdência Social (2009) para qualquer acidente, deve ser registrada a Comunicação de Acidente de Trabalho - CAT, regulamentada pelo Decreto n.2.172/97. A comunicação é importante, não apenas do ponto de vista previdenciário, mas também estatístico, epidemiológico, trabalhista e social. Lamentavelmente o Brasil ainda enfrenta a subnotificação dos registros de acidente de trabalho- AT (SANTANA et al., 2005).

Os acidentes e doenças do trabalho constituem no Brasil danos sociais preocupantes, pois além de comprometer a saúde e integridade física do trabalhador, desajustam grande parte das famílias. Os prejuízos dos acidentes de trabalho extrapolam o campo econômico e ganham uma dimensão social, visto que o aumento de consultas e internações demanda verbas públicas e privadas para o atendimento médico-hospitalar, além dos dias de afastamento para tratamento de doenças que resultam em impactos negativos na produtividade, entre outros (NERI et al., 2005).

Hennington e Monteiro (2006) sugerem a ineficiência na emissão de CAT, como uma das maiores responsáveis pela subnotificação de doenças relacionadas ao trabalho. Esta ineficiência pode envolver: negligência das empresas, desconhecimento do próprio trabalhador sobre a emissão da CAT, na dificuldade das relações entre trabalho e adoecimento, entre outros. Segundo Santana et al. (2005) atualmente a ocorrência de acidentes de trabalho não fatais é de grande magnitude e de relevância para a saúde pública. Há necessidade de se dar visibilidade à situação, o que torna importante as pesquisas relacionadas aos impactos da reestruturação produtiva no Brasil nas condições de trabalho e saúde dos trabalhadores.

Nesse contexto, o objetivo deste estudo foi o de investigar as possíveis relações existentes entre os afastamentos de trabalhadores portuários de transporte com vínculo empregatício e aspectos das condições e organização do trabalho de quando estavam ativos, a partir das percepções dos próprios trabalhadores.

\section{MATERIAIS E MÉTODOS}

Este estudo é parte da pesquisa intitulada "Afastamentos de trabalhadores portuários e relações com condições e aspectos da organização do trabalho", realizado junto a trabalhadores portuários afastados do trabalho, de diversas categorias profissionais, vinculados às operadoras portuárias e ao Sindicato dos Empregados Terrestres em Transportes Aquaviários e Operadores Portuários do Estado de São Paulo - SETTAPORT. Após o contato com o sindicato, apresentação do estudo e aceite em colaborar, foi obtida uma listagem de trabalhadores em situação de afastamento do trabalho.

Foi desenvolvido um estudo de caso, de caráter descritivo e exploratório, com ênfase em análises qualitativas. Foram convidados a participar motoristas e operadores de conjunto transportador elencados em listagem fornecida pelo respectivo sindicato. O critério utilizado para seleção dos participantes relacionou-se ao fato de estarem, no momento da coleta de dados, em situação de afastamento do trabalho. Foi feito contato telefônico, para realização do convite para participação na pesquisa. Em caso afirmativo, ocorria o agendamento da entrevista.

Para a realização das entrevistas semiestruturadas foi elaborado um roteiro, com questões referentes aos dados pessoais (idade, estado civil, escolaridade), ao perfil profissional, tempo de serviço, tempo de afastamento, entre outros, e aspectos do trabalho no setor portuário (descrição das atividades e das condições de trabalho, vivências de cada um deles no respectivo ambiente de trabalho, das dificuldades para a realização do trabalho, das causas do afastamento, entre outras).

$\mathrm{O}$ entrevistador buscou aprofundar, na medida do possível, alguns elementos presentes nos depoimentos e pertinentes ao estudo. As entrevistas, realizadas no período de outubro de 2010 a fevereiro de 2011, tiveram duração média de 50-60 minutos, foram gravadas e transcritas na íntegra para posterior análise de conteúdo por categorias (BARDIN, 2010).

O projeto foi aprovado pelo Comitê de Ética em Pesquisa da Universidade Federal de São Paulo (protocolo n. 1939/10), atendendo às Diretrizes e Normas de Pesquisa em Seres Humanos do Conselho Nacional de Saúde.

\section{RESULTADOS E DISCUSSÃO}

Abaixo foram elencados e discutidos os principais aspectos encontrados.

\section{I - Caracterização da população}

Participaram deste estudo seis $(\mathrm{n}=6)$ trabalhadores afastados do trabalho: quatro $(n=4)$ eram motoristas e dois $(\mathrm{n}=2)$ operadores de conjunto transportador, todos do gênero masculino, com idade entre 40 e 57 anos. A 
escolaridade variou entre primeiro e segundo grau completo e incompleto. $\mathrm{O}$ tempo de afastamento dos sujeitos variou entre dois e cinco anos, e todos recebiam auxílio-doença previdenciário pelo Instituto Nacional de Seguro Social (INSS). Quatro $(\mathrm{n}=4)$ deles foram afastados por lesão em região lombar (protusão e/ou hérnia discal lombar), e dois $(\mathrm{n}=2)$ por transtornos mentais (depressão).

Apesar de motoristas e operadores possuírem atribuições profissionais diferentes todos relataram serem motoristas, e executarem, no cotidiano de trabalho no terminal, as mesmas tarefas.

\section{Ritmo de trabalho e cumprimento de metas}

Em decorrência da grande exigência para o cumprimento das metas, os trabalhadores estavam submetidos a um ritmo intenso de trabalho, permanecendo grande parte de sua jornada dentro dos caminhões. Este fato gerava situações de desgaste, conforme os depoimentos abaixo:

“(...) não tinha como você não ficar muito tempo no caminhão, às vezes você nem descia do caminhão, era tão rápido o carregamento que você chegava, carregava e já saia, e lá já estavam esperando pra descarregar, volta de novo e não parava..." (motorista, 40 anos).

“(...) tinha que carregar durante a madrugada todinha... eu tinha que carregar no mínimo quinze a vinte contêineres, se a minha meta era vinte eu carregava os vinte, e assim ia (...) o encarregado anotava a hora que cheguei, o horário que eu saía, a hora que eu voltei. " (operador de conjunto transportador, 46 anos).

“(...) ali a gente andava só em círculos, a descarga são seiscentos e cinquenta metros, você fica ali o dia todo (..) descarrega pra pegar outro (contêiner), tinha hora que você não sabia se estava indo ou se estava voltando.." (motorista, 53 anos).

As situações de desgaste resultam de processos adaptativos que ocorrem em cada trabalhador, e são definidas como a perda da capacidade biopsíquica efetiva, não se configurando necessariamente como doença instalada, guardando a complexidade na compreensão dos agravos à saúde (PAPARELLI et al., 2010). Para Abrahão e Torres (2004), a impossibilidade de transformar ou adaptar as determinações da organização do trabalho tais como controle excessivo, ritmo intenso, entre outros, constituem fontes de insatisfação ou de sofrimento, a partir do momento em que os trabalhadores sentem seus recursos esgotados.

\section{Jornadas de trabalho e pausas}

Em alguns casos havia a exigência de jornada diária de trabalho de 12 horas, acumulando, eventualmente, para cada trabalhador, mais de 40 horas de trabalho semanais. Tal situação diferia da de outras equipes de trabalho portuário que faziam apenas seis horas diárias. Por permanecerem a maior parte do tempo de trabalho dentro dos caminhões, muitas vezes com poucas pausas para descanso e refeições, a situação de desgaste era reforçada.

“(...) o regime lá era seis horas, mas a gente fazia doze sempre, que era induzido a fazer. Não tinha horário de almoço... a gente brigava por causa disso... que a gente sempre que tinha um horário, almoçava na cabine do caminhão e ao mesmo tempo tinha que descarregar ou embarcar o contêiner..." (motorista, 53 anos).

“(...) fazia várias horas extras, eu pegava de manhã, sete da manhã às vezes você tava no terminal era nove horas da noite, já tinha passado mais de doze horas..." (motorista, 40 anos).

Em estudo realizado com motoristas de caminhão, as jornadas extensas de trabalho, o fato de terem de trabalhar a noite e a impossibilidade de escolher o horário de trabalho, foram possíveis causadores de distúrbios psíquicos menores (ULHÔA et al., 2010).

\section{Impactos na coluna vertebral}

Um dos trabalhadores entrevistados considerou o carregamento de contêineres_um grande risco a saúde física, especialmente à coluna lombar. $\mathrm{O}$ trabalhador ficava em geral dentro do caminhão, próximo ao navio, aguardando o contêiner ser içado pelo operador de portainer e colocado sobre o caminhão. Em algumas situações, o operador de portainer não esperava o contêiner encostar-se ao caminhão, e em determinada altura este era, repentinamente, solto sobre o caminhão e o motorista sentado no assento do caminhão (carreta) sofria o impacto da descida do contêiner (que pode pesar aproximadamente entre $2.000 \mathrm{~kg}$ a $30.000 \mathrm{~kg}$ ). Não havia possibilidade de sair do caminhão no momento do carregamento para não ocorrerem atrasos. Tais situações se repetiam ao longo da jornada de trabalho, uma vez que esta era uma das principais tarefas.

\section{“(...) o operador (de portainer) pega o contêiner no}


navio e traz pra fora e pra cima da carreta, então ele tem um espaço em cima, e que espera que está chegando perto do caminhão, (...) abaixava era pá, pá, batia na carreta né, descia e você chegava a sair do banco do caminhão, chegava a sair do banco do caminhão pelo impacto, então era cinquenta e poucas vezes por dia, eram sessenta impactos..." (motorista, 53 anos).

O impacto na coluna vertebral relacionado ao descarregamento do contêiner do navio configura-se como uma questão crítica e requer atenção e cuidado. Impactos são problemas frequentes junto aos motoristas, principalmente em região lombar, relacionados, sobretudo, a manutenção de posturas inadequadas (KILESSE, 2005; NEGRELLI, 2001). Seria necessária a realização de estudos específicos sobre esta questão além da intervenção de engenheiros para atenuar ou amenizar os impactos.

\section{Condições dos caminhões e dos trajetos realizados}

Os trabalhadores relataram que os caminhões apresentam condições precárias, sobretudo de conforto, e manutenção de componentes mecânicos, de forma que oferecem riscos para a segurança, e favorecem as vivências de situações de desgaste:

“(...) o caminhão não tinha condições nenhuma... assim eram velhos, não tinha manutenção apropriada, a gente trabalhava com os veículos às vezes sem freio na carreta, sem iluminação, então era muito caótica lá a manutenção, e a gente sofria com isso porque a gente não ia brigar..." (motorista, 53 anos).

“(...) o banco muitas vezes não tinha encosto, não tinha regulagem de peso, porque eu tô num determinado peso, e existe motorista lá que era gigante, o cara era bem gordo, bem mais gordo, quebrava o banco lá, ai você relatava (...) você era obrigado a ir com o caminhão quebrado e as costas não encostavam..." (motorista, 40 anos).

Os caminhões eram de propriedade das empresas ou alugados por elas e, em geral, era o supervisor que determinava qual caminhão deveria ser usado pelo motorista durante toda a jornada diária de trabalho. Itens como assento, encosto, tipo de câmbio e direção, são elementos importantes para evitar problemas na coluna e demais adoecimentos decorrentes dessa atividade, quando oferecem maior conforto e adequabilidade do trabalhador ao instrumento de trabalho (KILESSE, 2005; NERI et al., 2005).

\section{Aspectos ambientais}

Os entrevistados estavam expostos aos riscos ambientais inerentes ao contexto do Porto, como: calor, frio, ruído e poeira:

“(...) ali faça chuva, faça sol, tinha que trabalhar né... tava exposto a tudo lá né, exposto à poeira, sol demais né, chuva, vento, tudo né..." (motorista, 52 anos).

“(...) sujeito aos intempéries do tempo (...) tinha chuva, tinha sol, vento, eu trabalhava direto lá que não podia parar... a gente era bem judiado ali." (motorista, 53 anos).

Verificou-se que os trabalhadores executavam as tarefas sem pausas, mesmo em condições de chuva, vento, calor excessivo, entre outros. Em estudo de Kilesse (2005) as exigências do trabalho dos motoristas fazem com que essa profissão seja caracterizada como fatigante, pois os trabalhadores permanecem constantemente expostos a ruídos, temperaturas elevadas, vibrações, entre outros.

\section{Reconhecimento no trabalho}

Alguns entrevistados relataram pouco ou nenhum reconhecimento no trabalho, e pouca possibilidade para escuta por parte da chefia, conforme demonstrado no depoimento abaixo:

"A chefia não ouvia a gente (...)motorista ali não tinha valor nenhum, a gente não tinha voz nenhuma (...), então a gente se sentia um lixo ali, sentia desde que você entrava, as pessoas já tratavam você como um trapo, era horrivel, saia de lá arrasado...." (motorista, 53 anos).

Em geral, a falta de reconhecimento no trabalho provoca o sentimento de desqualificação, de inutilidade, de revolta, e pode comprometer o sentido do trabalho. O reconhecimento permite o desenvolvimento da subjetividade e a transformação do sofrimento em prazer no trabalho (DEJOURS, 1992; DEJOURS et al., 1994; LANCMAN, 2004; DEJOURS, 2008).

Um dos exemplos mais relevantes relatados pelos entrevistados explicita-se pela falta de segurança no trabalho, destacando a invisibilidade destes perante os 
demais trabalhadores e as chefias:

“(...) é falta de segurança.. para falar em virar o caminhão, tinha que gritar para o cara, senão o cara ía derrubar o contêiner direto no chão, é uma loucura.." (motorista, 52 anos)

"Eu ficava às vezes embaixo do contêiner descendo (...), muita gente amassou a cabine, encostava lá (contêiner) e amassava a cabine, o contêiner bate em cima da cabine do caminhão. Tinha que ficar com o caminhão engatado, se acontece alguma coisa, você puxava para frente ou para trás."(operador de conjunto transportador, 46 anos)

Neste contexto, acidentes graves e/ou fatais às vezes ocorriam, e alguns entrevistados presenciaram mortes de colegas, vivenciando situações críticas que podem ser traumáticas para os sujeitos, o que impulsionaria entre outros aspectos, o desenvolvimento dos quadros depressivos encontrados em alguns entrevistados, conforme os depoimentos abaixo:

“(...) a carreta também atropelou, matou um rapaz (...), o cara tava fazendo uma operação, ele tava ali e o caminhão pegou o cara, partiu o cara no meio, na frente da gente.. "(motorista, 53 anos)

“(...) Ah eu vi coisas que me chocaram demais, foram os acidentes que eu vi, e as pessoas não ligavam para as outras, ligavam para a mercadoria (...) se preocupavam primeiro com o que tava dentro, em cima do caminhão: e aí avariou o contêiner? Nem perguntava se o motorista tava vivo ou não (...), o mais importante é a mercadoria, é o contêiner, sei lá, não dá valor para você.." (motorista, 40 anos)

Aparentemente havia maior valorização da carga transportada, do que da vida dos trabalhadores, o que acarretava em sofrimento. Neste contexto, aqueles que, passaram por vivências traumáticas podem ter afetada sua saúde mental. Há uma tendência geral das empresas em serem "omissas" aos fatos e a sua responsabilidade sobre a saúde dos trabalhadores que nela estão inseridos, e, consequentemente, culpabilizar o trabalhador pelo acidente. $\mathrm{O}$ trabalhador pode adoecer ou não mentalmente em decorrência dos constrangimentos vivenciados em seu cotidiano de trabalho e quando as estratégias de defesa contra o sofrimento encontram-se esgotadas (DEJOURS, 1992; DEJOURS et al., 1994; DEJOURS, 2008).

\section{CONSIDERAÇÕES FINAIS}

Neste estudo foram identificados os principais riscos à saúde dos motoristas e operadores de conjunto transportador que atuam nos terminais portuários. São eles: ritmo intenso de trabalho, poucas pausas, jornadas extensas de trabalho, condições precárias dos caminhões, pouco reconhecimento no trabalho e, exposição aos aspectos ambientais (vento, chuva, sol, entre outros). Tais situações podem ocasionar acidentes e consequentemente, situações de afastamento do trabalho, como identificados pelos trabalhadores.

Impactos violentos sobre a coluna vertebral podem ocasionar protusão discal ou mesmo hérnia discal, com agravos maiores se houver exposição também a outras situações, como vibrações durante a jornada de trabalho, que podem advir de condições inadequadas de assento e amortecedor, das ruas (trajetos), entre outros, e a não comunicação ou atenção adequada dada ao momento da lesão ocorrida.

A falta de segurança no trabalho em alguns procedimentos, e a possibilidade de presenciar acidentes fatais, pode ser uma vivência muito traumática para os sujeitos. A mercadoria ter mais valor para a empresa do que a própria vida do trabalhador nos faz pensar em qual seria o sentido do trabalho para o trabalhador e para a própria empresa, as repercussões desta situação para o adoecimento mental, além das reflexões sobre a necessidade de ações mais eficazes para a segurança, humanização das situações e contextos de trabalho.

Todos os participantes deste estudo recebiam auxílio-doença previdenciário, o que ocorre em geral em casos de indefinição do nexo causal, sugerindo entre outros, a ineficiência na emissão do Comunicado de Acidente de trabalho - CAT. Com isso, não se pode comprovar que há relações entre as situações relatadas e os afastamentos, mas ao menos se pretende promover reflexões sobre as vivências dos sujeitos com relação ao trabalho. Muitas vezes estes desconhecem seus direitos, o que reforça a vivência da sensação de injustiça, já que não acessam os recursos necessários para reverter esta situação.

Este estudo enfatizou a relevância de aspectos das condições e da organização do trabalho na saúde e nos afastamentos de trabalhadores portuários das categorias "motorista" e "operador de conjunto transportador". Apontamos para a necessidade de intervenções nas situações elencadas, a partir da atuação de equipes multidisciplinares nas quais o Terapeuta Ocupacional pode contribuir, visando à prevenção dessas situações e consequentemente a diminuição de acidentes e 
afastamentos desses trabalhadores.

Pesquisas futuras devem aprofundar as questões trazidas neste estudo, não só junto a essas categorias profissionais do trabalho portuário, mas também a outras.

AGRADECIMENTOS: Os autores agradecem ao Sindicato SETTAPORT pelo apoio e colaboração.

\begin{abstract}
ALENCAR, M. C. B.; BIZ, R. A. M. Working conditions and organisational aspects and the retirement of port workers of transportation. Rev. Ter. Ocup. Univ. São Paulo, v. 23, n. 3, p. 208 15, set./dez. 2012.
\end{abstract}

\begin{abstract}
The objective of this study was to investigate possible relationship in between retirement from port workers of transportation and aspects of work conditions and organizational aspects when they were active workers, by their perceptions. This research is qualitative and a study case, characterized by descriptive and exploratory. There were selected six $(n=6)$ port workers in retirement from work situation, in between them drivers and transportation operators, through a list from a port workers' syndicate of Santos-SP. It was elaborated a script with semi structured questions about occupational profile, retirement from a work situation, work conditions and organizational aspects, and others, to realize recorded interviews and integral transcription for categorical content analyses. From the subjects of this research, all of them $(n=6)$ were masculine sex, age in between 40 to 57 years old, four of them $(n=4)$ were retired of work by back disease, and two $(n=2)$ by mental disorders. Health risks identified: accelerated rhythm of work, repetitive, short pauses, long journeys of work, poor conditions of the trucks, little recognition at work, absent of security, and others. This study suggests a relationship in between working conditions and organisational aspects and the retirements from work, and emphasizes that interventions are needed to promote health and security of port workers.
\end{abstract}

KEYWORDS: Sick leave; Port work; Work/psychology; Working conditions; Occupational health; Employment/organization\& administration; Ocupations/manpower; Automobile driving/ psychology; Occupational diseases/psychology.

\section{REFERÊNCIAS}

ABRAHÃO, J. I.; TORRES, C. C. Entre a organização do trabalho e o sofrimento: o papel da mediação da atividade. Rev. Produção, v. 14, n. 6, p. 67-76, 2004.

AGUIAR, M. A. F.; JUNQUEIRA, A. P.; FREDDO, A. C. M. O Sindicato dos Estivadores do Porto de Santos e o processo de modernização portuária. Rev. Admin. Pública, Rio de Janeiro, v. 40, n. 6, p. 997-1017, 2006.

ARAÚJO, M. D., CABRAL, C. O., SACCHI, R. A., ANDRADE, R. B., ZANOTTI, S. V. Solidariedade e segurança: coletivos de trabalho nos portos capixabas. In: CONGRESSO NACIONAL DE SEGURANÇA E SAÚDE NO TRABALHO PORTUÁRIO E AQUAVIÁRIO, 1., 2000. Anais. São Paulo: Ed. Fundacentro, 2000. p. 49-60.

BARDIN, L. Análise de conteúdo. Lisboa: Edições 70, 2010.

BRASIL. Lei n.8.213, de 24 de julho de 1991. Dispõe sobre os planos de benefícios da Previdência Social e dá providencias. Diário Oficial da República Federativa do Brasil, Brasília, DF, 14 agosto, 1991.
BRASIL. Ministério do Trabalho e Emprego. Manual do trabalho portuário e ementário. Brasília: MTE/SIT, 2001.

BRASIL. Ministério da Previdência Social. Manual de instruções para o preenchimento da Comunicação de Acidente de Trabalho-CAT. Disponível em: http://www.mpas. gov.br/arquivos/office/4_101112-101538-142.pdf. Acesso em fev. 2012.

DEJOURS, C. A loucura do trabalho: estudo de psicopatologia do trabalho. São Paulo: Cortez, 1992. p. 11-26.

DEJOURS, C.; ABDOUCHELI, E.; JAYET, C. Psicodinâmica do trabalho. São Paulo: Atlas, 1994.

DEJOURS, C. Addendum da psicopatologia à psicodinâmica do trabalho. In: LANCMAN, S.; SZNELWAR, L. I. Christophe Dejours - da psicopatologia à psicodinâmica do trabalho. Rio de Janeiro: Ed. Fiocruz; Brasília: Ed. Paralelo, 2008.

DIÉGUEZ, C. R. M. A. Reestruturação do trabalho portuário pós privatização [Tese - Doutorado Ciências Sociais]. São Paulo, 
2009. Universidade Estadual de Campinas - UNICAMP,

HENNINGTON, E.A.; MONTEIRO, M. O perfil epidemiológico dos acidentes de trabalho no Vale dos Sinos e o sistema de vigilância do trabalhador. História, Ciên. Saúde-Manguinhos, vol.13, n.4, p.865-876, 2006.

KILESSE, R. Fatores ergonômicos em posto de trabalho de motoristas de caminhão [Tese de Doutorado - Engenharia Agrícola). Viçosa, 2005. Universidade Federal de Viçosa, Minas Gerais.

LANCMAN, S. Construção de novas teorias e práticas em Terapia Ocupacional, saúde e trabalho. In: LANCMAN, S. (Org). Saúde, trabalho e Terapia Ocupacional. São Paulo: Ed. Roca, 2004.

MACHIN, R., COUTO, M.T., ROSSI, C. Representações de trabalhadores portuários de Santos - SP sobre a relação trabalhosaúde. Saúde Sociedade, São Paulo, v. 18, n. 4, 2009.

NEGRELLI, W. F. Hérnia discal: procedimentos de tratamento. Acta Ortop. Bras., v. 9, n. 1, p. 39-45, 2001.

NERI, M.; SOARES, W. L.; SOARES, C. Condições de saúde no setor de transporte rodoviário de cargas e de passageiros: um estudo baseado na Pesquisa Nacional por Amostra de Domicílios. Cad.
Saúde Pública, Rio de Janeiro, v. 21, n. 4, p. 1107-1123, 2005.

PAPARELLI, R.; SATO, L.; OLIVEIRA, F. A saúde mental relacionada ao trabalho e os desafios aos profissionais da saúde. Rev. Bras. Saúde Ocup., v. 36, n. 123, p. 118-127, 2011.

SANTANA, V.; NOBRE, L.; WALDVOGEL, B. C. Acidentes de trabalho no Brasil entre 1994 e 2004: uma revisão. Ciên. Saúde Coletiva, v. 10, n. 4, p. 841-855, 2005.

STACCHINI, F. A prevenção dos riscos profissionais no trabalho portuário. In: CONGRESSO NACIONAL DE PREVENÇÃO DE ACIDENTES DE TRABALHO, 17. Anais. São Paulo: Fundacentro, 1978. p. 120-127.

ULHÔA, M. A.; MARQUEZE, E. C.; LEMOS, L. C.; SILVA, L. G.; SILVA, A. A.; NEHME, P.; FISCHER, F. M.; MORENO, C. R. C. Distúrbios psíquicos menores e condições de trabalho em motoristas de caminhão. Rev. Saúde Pública, v. 44, n. 6 , p.1130-1136, 2010.

VILLARINHO, L.; BEZERRA, I.; LACERDA, R.; LATORRE, M. R. D. O.; PAIVA, V.; STALL, R.; HEARST, N. Caminhoneiros de rota curta e sua vulnerabilidade ao HIV, Santos, SP. Rev. Saúde Pública, v. 36, n. 4, p. 61-67, 2002.

Recebido para publicação: 28/03/2012.

Aceito para publicação: 21/09/2012. 